had resolved by six months. Provided adequate explanation of the condition is given to the parents, this approach is readily accepted and avoids the potential complications of the other methods of treatment currently recommended.

We thank the Chris Fund for financing secretarial help.

' Capraro VJ, Greenberg H. Adhesions of labia minora, a study of 50 patients Obstet Gynecol 1972;39:65-9.

Aribarg A. Topical oestrogen therapy for labial adhesions in children. $\mathrm{Br} \mathcal{F}$ Obste Gynaecol $1975 ; 82: 424-5$.

Lewis GT. Fused labia minora. Br Med f 1983;287:886

lin P, Adams JR, Nalle BC. Vulvar fusion. F Urol 1949;62:75-9.

Br Med f 1983;287:1725.

(Accepted 1 fune 1984)

Sub-Department of Paediatric Surgery, Children's Hospital, Sheffield S10 2TH

$S$ D JENKINSON, MB, CHB, senior house officer

A E MACKINNON, MB, FRCS, consultant surgeon

\section{Jarisch-Herxheimer reaction in falciparum malaria?}

During the treatment of falciparum malaria with Fansidar (pyrimethamine and sulphadoxine) a secondary rise in temperature is sometimes seen. We have recently studied such a case in detail.

\section{Case report}

A 20 year old man was admitted to hospital two weeks after returning to Denmark from Tanzania. Blood slides on admission showed infection with Plasmodium falciparum. He was given three tablets of Fansidar and his temperature declined from $40.3^{\circ} \mathrm{C}$ to $37.0^{\circ} \mathrm{C}$ in 16 hours (see figure). Ten hours later his temperature began to rise again. This was associated with malaise, headache, backpain, nausea, vomiting, and tachycardia. Suspecting failure of treatment, as no other focus of infection was found, we gave another three tablets of Fansidar. Fresh blood films showed that the maximal parasitaemia of 428 infected erythrocytes per 50 leucocytes had disappeared several hours before the new temperature rise, leaving the patient free of parasites for at least eight hours before the fever rose to its peak. During the second period of fever the total leucocyte count was $4 \cdot 4 \times 10^{9} / 1$. Differential count showed a left shift in the granulocytes, lymphopenia, and absolute eosinopenia.

On questioning the patient it emerged that in Tanzania he had suspected that he had malaria and treated himself with Fansidar. His symptoms had then disappeared in 36 hours and he had had no secondary reaction. He had never used Fansidar as a prophylactic agent but always chloroquine $500 \mathrm{mg}$ a week. He was not known to be allergic to any medicine, including sulphonamides.

\section{Comment}

After the start of treatment this patient initially became well and his fever declined. The parasitaemia was cleared, from a maximum of about $1 \%$ infected erythrocytes in the 18 th hour to almost none in the 38th hour. Nevertheless, simultaneously he again developed acute symptoms, with fever and a rise in the heart rate. Such a picture is similar to the Jarisch-Herxheimer reaction, which is best known after the treatment of syphilis but which has also been reported after the treatment of other spirochaetal infections, some bacterial infections, and trypanosomiasis. ${ }^{1}$ The typical features of this are fever, chills, headache, malaise, myalgia, arthralgia, nausea, vomiting, and exacerbation of skin lesions ${ }^{2}$; a rise in the heart rate; and changes in blood pressure. During the reaction the typical haematological finding is leucocytosis with lymphopenia, eosinopenia, and a shift to the left in the granulocytes. ${ }^{3}$ In malaria, in contrast, neutropenia is the commonest finding.
The reaction in our patient after treating him for malaria resembled the classic Jarisch-Herxheimer reaction, firstly in its clinical features, secondly, in the changes in the temperature and pulse rate, and lastly in the changes in the leucocyte count. In patients with neurosyphilis treated with penicillin the reaction lasts for about 32 hours, in primary syphilis for 12 hours when penicillin is given intravenously ${ }^{2}$ and for
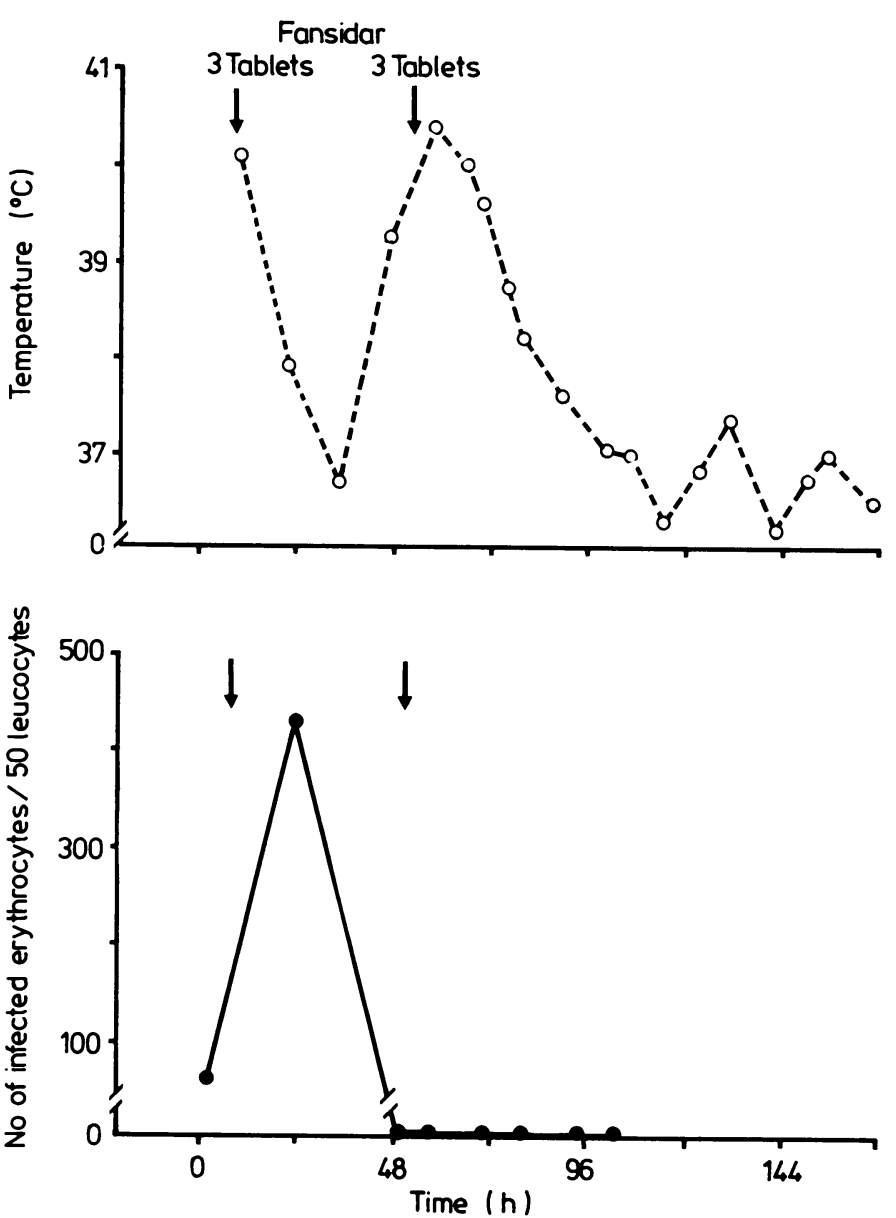

Course of temperature and parasitaemia during treatment of falciparum malaria treated with sulfadoxin/pyrimetamin (Fansidar). Arrows show when patient received Fansidar ( 3 tablets each time).

24 hours when mercury is given. ${ }^{4}$ This compares closely with the 48 hours seen in this patient. As in syphilis it is not known why some people develop this reaction and others do not; immunological factors may have a role, as might endotoxins as well. ${ }^{5}$

' Bryceson ADM. Clinical pathology of the Jarisch-Herxheimer reaction. I Infect

Dis $1976 ; 133: 696-704$.
Aronson IK, Soltani K. The enigma of the pathogenesis of the Jarisch-Herxheimer reaction. Br f Vener Dis 1976;52:313-5.

reaction. Br 7 Vener Dis $1976 ; 52: 313-5$. Acta Dermato-venereol (Stockh) $1966 ; 46$. $136-43$.

4 Herxheimer K, Krause P. Ueber eine bei Syphilitischen vorkommende Quecksilberreaction. Dtsch Med Wochenschr 1902;28:895-7.

Grond K, Fritz J, Sandhofer M. Zur immunologischen Dynamik der JarischHerxheimer-Reaktion. $Z$ Hautkr 1979;54:191-6.

(Accepted 24 April 1984)

Department of Internal Medicine, Svendborg Hospital, DK-5700, Svendborg, Denmark

POUL-ERIK KOFOED, MD, physician

Correspondence to: Kløvervaenget 26D-21, DK-5000 Odense C, Denmark. 